\title{
How do treatments for chronic fatigue syndrome work? Exploration of instrumental variable methods for mediation analysis in PACE - a randomised controlled trial of adaptive pacing therapy, cognitive behaviour therapy, graded exercise therapy, and specialist medical care
}

\author{
Kimberley Goldsmith ${ }^{1 *}$, Trudie Chalder ${ }^{1}$, Peter White ${ }^{2}$, Michael Sharpe $^{3}$, Andrew Pickles $^{1}$
}

From Clinical Trials Methodology Conference 2011

Bristol, UK. 4-5 October 2011

\section{Objectives \\ Background}

Chronic fatigue syndrome (CFS) is characterised by chronic disabling fatigue. The PACE trial compared four treatments for CFS and found that for therapies added to specialist medical care (SMC), cognitive behaviour therapy (CBT) and graded exercise therapy (GET) were more effective than adaptive pacing therapy (APT) and SMC alone in improving physical function and fatigue. What are the mechanisms of these treatments? CBT and GET may affect outcomes through thought processes and behaviours (mediators). Traditional Baron, Judd and Kenny (BJK) methods for estimating mediation effects can be subject to bias; instrumental variable methods (IV) can address this problem. The aims were:

To explore potential IVs for causal analysis of mediation in PACE.

To compare IV estimates to those obtained using BJK methods, which are unbiased only under restrictive assumptions such as no unmeasured confounding.

\section{Methods}

Two treatment arms were compared at a time. BJK methods were applied using three ordinary least squares (OLS) regression models. IV methods were applied by

'Institute of Psychiatry, King's College London, DeCrespigny Park, London, SE5 8AF, UK

Full list of author information is available at the end of the article compiling a list of baseline variables that could act as IVs in interaction terms with treatment arm and then assessing these using OLS with the mid-treatment measurement of the putative mediator as the outcome. Instrument strength was assessed using the $\mathrm{R}^{2}$ change between models with main effects only and with the interaction term. Two-stages least squares regression (2SLS) was used to estimate effects in the presence of IVs. Collective instrument strength was assessed using an $\mathrm{F}$ test and partial $\mathrm{R}^{2}$.

\section{Results}

The IVs were weak, with a maximum $\mathrm{R}^{2}$ change of 0.03 . The five strongest IVs were therefore used in the 2SLS in each case. There was modest mediation of CBT and GET effects (approximately 20\% of the total effect). The IV-derived estimators were somewhat different in magnitude than the BJK estimators and were less precise. There is scope for modelling a common effect of mediators on outcomes across trial arms.

\section{Conclusions}

There was evidence for modest mediation of CBT and GET effects. Potential IVs for the study of PACE treatment mechanisms can be found, however, these were weak. Combining trial arms may allow for more efficient analysis using IVs. 


\section{Author details}

'Institute of Psychiatry, King's College London, DeCrespigny Park, London,

SE5 8AF, UK. 'Wolfson Institute of Preventative Medicine, Queen Mary,

University of London, EC1M 6BQ, UK. ${ }^{3}$ Department of Psychiatry, University

of Oxford, OX3 7JX, UK.

Published: 13 December 2011

doi:10.1186/1745-6215-12-S1-A144

Cite this article as: Goldsmith et al:: How do treatments for chronic fatigue syndrome work? Exploration of instrumental variable methods

for mediation analysis in PACE - a randomised controlled trial of

adaptive pacing therapy, cognitive behaviour therapy, graded exercise

therapy, and specialist medical care. Trials 2011 12(Suppl 1):A144.

Submit your next manuscript to BioMed Central and take full advantage of:

- Convenient online submission

- Thorough peer review

- No space constraints or color figure charges

- Immediate publication on acceptance

- Inclusion in PubMed, CAS, Scopus and Google Scholar

- Research which is freely available for redistribution

Submit your manuscript at www.biomedcentral.com/submit 